\title{
Knowledge, Attitude, and Practices toward the COVID-19 Pandemic among the Indian General Population: A Cross-Sectional Survey
}

\author{
Lakshmi Venkata Simhachalam Kutikuppala, A. N. Syamasundara Kiran', Tarun Kumar Suvvari² \\ Final Year MBBS, Konaseema Institute of Medical Sciences and Research Foundation, Amalapuram, ${ }^{2}$ Second Year MBBS, Rangaraya Medical College, Kakinada, \\ Andhra Pradesh, 'Department of Physiology, Government Institute of Medical Sciences, Greater Noida, Uttar Pradesh, India
}

\section{Abstract}

Background: Coronavirus disease 2019 (COVID-19) disease is highly infectious, and fever, dry cough, fatigue, myalgia, and dyspnea are the main clinical symptoms of the disease. There is a necessity to understand the public's awareness of COVID-19 to facilitate the outbreak management of COVID-19 in India. Collection of knowledge, attitude, and practice (KAP) information regarding outbreaks has long been useful in apprising prevention, control, and mitigation measures during such outbreaks. Objectives: The study objective was to evaluate knowledge levels, prevailing attitudes, and practices among the general population of India about the COVID-19 pandemic and to rule out barriers concerned with practicing risk reduction behaviors. Methodology: A cross-sectional study was conducted online among the general population of India during the lockdown period. The KAP toward COVID-19/severe acute respiratory syndrome-coronavirus-2 infection and prevention were assessed by using a self-administered questionnaire with 32 questions. The KAP assessment was carried out by assigning scores to the variables. SPSS version 24.0 and Chi-square test were used for statistical analysis. Results: A total of 1292 people had participated in the survey, and their mean age was 29.43 years. Overall, $81 \%$ of the participants had good knowledge, $77 \%$ of the participants had a positive attitude, and $83.5 \%$ of the participants were following good practices. Nearly $94 \%$ of the participants are confident that India can overcome COVID-19, and $97.7 \%$ of the participants wore masks when they went out. Conclusion: Health education campaigns and awareness events targeting the general population can enhance knowledge and attitudes of the people to the pandemic and potentiate better practices in facing the crisis.

Keywords: 2019-nCoV disease, COVID-19, COVID-19 pandemic, SARS-CoV-2 infection

\section{INTRODUCTION}

Coronavirus disease 2019 (COVID-19) is a global pandemic caused by severe acute respiratory syndrome-coronavirus-2 (SARS-CoV-2). These coronaviruses are a large family of enveloped, positive-sense, single-stranded RNA viruses. SARS-CoV-2 spreads primarily between people by close contact and through respiratory droplets produced during coughing or sneezing by an infected person. Four pandemics were caused via the emergence of novel influenza viruses in the past century such as H1N1 Spanish flu (1918), H2N2 Asian flu (1957), the H3N2 Hong Kong flu (1968), and the H1N1 swine flu (2009). ${ }^{[1]}$

COVID-19 disease is highly infectious, and fever, dry cough, fatigue, myalgia, and dyspnea are the main clinical symptoms of

\begin{tabular}{|l|l|}
\hline \multicolumn{2}{|c|}{ Access this article online } \\
\hline Quick Response Code: & Website: \\
\hline & www.ijrc.in \\
\hline & \\
\hline
\end{tabular}

the disease. The severe stage of the disease is characterized by acute respiratory distress syndrome, septic shock, difficult-to-tackle metabolic acidosis, and bleeding and coagulation dysfunction. ${ }^{[2]}$ The World Health Organization (WHO) has declared COVID-19 as a public health emergency of international concern on January 30,2020 , and called all countries of the world for collaborative efforts to prevent the rapid spread of COVID-19. ${ }^{[3]}$

Address for correspondence: Mr. Tarun Kumar Suvvari, Rangaraya Medical College, Kakinada, Andhra Pradesh, India. E-mail: tarunkumarsuvvari234@gmail.com

This is an open access journal, and articles are distributed under the terms of the Creative Commons Attribution-NonCommercial-ShareAlike 4.0 License, which allows others to remix, tweak, and build upon the work non-commercially, as long as appropriate credit is given and the new creations are licensed under the identical terms.

For reprints contact: WKHLRPMedknow_reprints@wolterskluwer.com

How to cite this article: Kutikuppala LV, Kiran AN, Suvvari TK. Knowledge, attitude, and practices toward the COVID-19 pandemic among the Indian general population: A cross-sectional survey. Indian J Respir Care 2021;10:88-92.

Received: $23-07-2020$ Accepted: 07-09-2020 Published: $31-01-2021$ 
As on June 9, 2020, there are 7,263,730 confirmed cases, and 411,193 deaths were reported, globally affecting 213 countries and territories around the world and two international conveyances: The Diamond Princess Cruise ship in Japan and M. S. Zaandam Cruise ship in America. ${ }^{[4]}$ India has 274,758 positive cases, with 7719 deaths in 34 states and union territories of India, in which Maharashtra has the highest number of 90,787 positive cases followed by Tamil Nadu with 34,914 cases till June 9, 2020. ${ }^{[5]}$

The measures that have been adopted by most of the countries to control the COVID-19 transmission include suspension of public transportation, closing of public spaces, close management of communities, isolation, and care for infected people and suspected cases. The experiences learned from the previous SARS outbreak in 2003 suggest that knowledge and attitudes toward infectious diseases are associated with a level of panic and emotional disturbances among the population that can further complicate attempts to prevent the spread of the disease. There is a necessity to understand the public's awareness of COVID-19 at this critical moment to facilitate the outbreak management of COVID-19 in India. This study is chosen to assess people's adherence and awareness to the control measures, which is largely affected by their knowledge, attitudes, and practices (KAP) toward COVID-19. The aim of the study was to evaluate the KAP of the Indian population toward COVID-19 during the rapid acceleration phase of the COVID-19 outbreak.

\section{Methodology}

A cross-sectional study was conducted among the general population of India during the period from June 3 to June 10,2020 . As it was a lockdown period, the study was conducted through an online survey by using the KoBo Toolbox questionnaire forms. Brief information containing the title, objectives, voluntary participation, and declaration of confidentiality about their information was attached to the survey form. This study was not restricted to a particular state/city, therefore involving many places across the country, making it a pan-India study. The inclusion criteria of this study were population aged 18 years or above, people who had completed their posthigh school study, and those who are residents of India. People who were not willing to participate were excluded from the study. Only people with high school or higher level of education were surveyed because they had to be able to handle the Google Forms and needed to understand a few medical terms.

The study was a basic KAP study and hence, ethics committee approval was waived off. Necessary permission was given by the institution Government Institute of Medical Sciences, Greater Noida, Uttar Pradesh, India.

The questionnaire began with the consent of participation, followed by sociodemographic and background information including age, gender, occupation, education, marital status, and current place of residence, followed by questions regarding KAP pertaining to COVID-19.
The KAP questionnaire was developed according to the information and guidelines on COVID-19 given by the WHO and the Centers for Disease Control and Prevention (CDC). The questionnaire had a total of 32 questions. The knowledge questions were 12 , of which 6 were on virology and transmission, 4 on clinical features, and 2 on the treatment of COVID-19. The questions corresponding to attitude were ten in number based on attitudes and risk perception toward COVID-19, including attitude toward control of COVID-19 and views and impact of the lockdown on them. The practice questions were ten, based on the practice of preventive measures against COVID-19, followed by implementing them inside the house and when going outside. The correct answer was an allotted score of 1 point, and an incorrect answer had no score. The total score range of KAP were classified as $0-12$, $0-10$, and $0-10$, respectively.

\section{Statistical analysis}

Data were entered into Excel spreadsheets, and statistical analysis was performed using the Statistical Package for Social Sciences (SPSS) version 24.0 (IBM Corp. Released 2016. IBM SPSS Statistics for Windows, Version 24.0. Armonk, NY: IBM Corp) and was presented by using mean and standard deviation. Categorical variables were presented by using frequency and percentage. Descriptive statistics were used to determine the sociodemographic factors and KAP scores. The KAP assessment was carried out by assigning scores to the variables. A Chi-square test was used to determine the role of sociodemographic characteristics on KAP. The statistical significance level was set at $P<0.05$ (two sided).

\section{RESULTS}

A total of 1292 people participated in the survey. Demographic data, marital status, and level of education are shown in Table 1.

The score of 8 and above in "knowledge domain" was considered a good score. The mean knowledge score was 8.75 [Table 2], and $81 \%$ of the study participants $(n=1047)$ were considered to have good knowledge. Source of information about the coronavirus for $88.85 \%$ of the participants was mobile phone and television. Nearly $92.5 \%$ of the participants had an idea that COVID-19 refers to the disease name and not a virus, and $87.2 \%$ of the participants knew that SARS-CoV-2 is the virus causing COVID-19. Nearly $90 \%$ of the study participants had an idea that COVID-19 is being spread by respiratory droplets of infected persons, and $83.3 \%$ of the participants agreed that the incubation period of COVID-19 is 1-14 days. Almost $91 \%$ of the participants knew that people with preexisting medical conditions and old-age people are at high risk of developing serious illness toward COVID-19. Nearly $82 \%$ of the people had reported that fever, dry cough, fatigue (weakness), and shortness of the breath are the most common symptoms of COVID-19.

A score of 7 and above in attitude domain was considered a good score. The mean attitude score was 7.56 [Table 2], and $77 \%$ of the study participants $(n=995)$ have a positive attitude. 


\begin{tabular}{|c|c|}
\hline & Number of individuals $(n=1292), n(\%)$ \\
\hline \multicolumn{2}{|l|}{ Age } \\
\hline $18-30$ & $802(62)$ \\
\hline $31-43$ & $400(31)$ \\
\hline 44 and above & $90(7)$ \\
\hline \multicolumn{2}{|l|}{ Gender } \\
\hline Male & $723(56)$ \\
\hline Female & $569(44)$ \\
\hline \multicolumn{2}{|l|}{ Religion } \\
\hline Hinduism & $943(73)$ \\
\hline Christianity & $182(14)$ \\
\hline Islam & $103(8)$ \\
\hline Others & $64(5)$ \\
\hline \multicolumn{2}{|l|}{ Educational status } \\
\hline High school & $65(5)$ \\
\hline Intermediate/diploma & $103(8)$ \\
\hline Undergraduate & $413(32)$ \\
\hline Graduate & $517(40)$ \\
\hline Postgraduate & $194(15)$ \\
\hline \multicolumn{2}{|l|}{ Occupation } \\
\hline Student & $426(33)$ \\
\hline Health-care worker & $168(13)$ \\
\hline Government sector & $233(18)$ \\
\hline Private sector & $294(22.75)$ \\
\hline Unemployed & $52(4)$ \\
\hline Other & $119(9.25)$ \\
\hline \multicolumn{2}{|l|}{ Marital status } \\
\hline Unmarried & $581(45)$ \\
\hline Married & $711(55)$ \\
\hline \multicolumn{2}{|l|}{ Type of family } \\
\hline Nuclear & $1111(86)$ \\
\hline Joint & $181(14)$ \\
\hline \multicolumn{2}{|l|}{ Current place of residence } \\
\hline Urban & $736(57)$ \\
\hline Rural & $556(43)$ \\
\hline \multicolumn{2}{|l|}{ Region of India } \\
\hline North India & $413(32)$ \\
\hline South India & $879(68)$ \\
\hline
\end{tabular}

Table 2: Mean score values and standard deviations of knowledge, attitude, and practices $(n=1292)$

\begin{tabular}{lc}
\hline & Mean score \pm SD \\
\hline Knowledge & $8.75 \pm 1.357$ \\
Attitude & $7.56 \pm 0.726$ \\
Practices & $8.11 \pm 0.782$ \\
\hline
\end{tabular}

SD: Standard deviation

Over $43.5 \%$ of the people chose that the current death rate of COVID-19 is very low. Only $12 \%$ of the participants had a travel history to another state, and no participant had a travel history to other countries. Most of the people who had travel history are under home quarantine. Concerning people and the zones they were residing, $59 \%$ of the participants were from the green zone, $21 \%$ from orange zone, and $20 \%$ from red zone.
The score of 7 and above in practices was considered a good score. The mean practice score was 8.11 [Table 2], and 83.5\% of the study participants $(n=1079)$ had good practices. Nearly $97.7 \%$ of the people always wore the mask, in which $66.7 \%$ were using reusable masks and $33.2 \%$ were using disposable marks. Almost $84 \%$ of the people who were using reusable masks were disinfecting the masks. Nearly $96.6 \%$ of the people were maintaining social distance when they went outside. Almost $61.2 \%$ of the participants were using sanitizers during travel or when going outside. Allopathic multivitamin tablets and homeopathic tablets such as arsenic Alb 30 were used by $39.3 \%$ and $35.2 \%$ of the participants, respectively. Place of residing zone versus fear of infection and fear of financial loss versus supporting lockdown extension is represented in Figures 1 and 2, respectively.

The KAP question responses among the study participants $(n=1292)$ are represented in Table 3. Responses to the study population regarding KAP in relation to education $(n=1292)$ are shown in Table 4.

For the knowledge question regarding any specific medicine to present or treat COVID-19 among the participants who responded, no more than half were graduates $(39.5 \%)$ and undergraduates $(32.3 \%)$. There was a statistically significant difference with $P=0.0381$ [Table 4]. For the attitude domain, whether India can overcome COVID-19 pandemic or not in relation to education, graduates $(40.3 \%)$ followed by undergraduates $(31.6 \%)$ responded positively as "yes." There was a statistically significant difference with $P=0.0286$ [Table 4]. For the attitude question, whether they had any fear of getting infected with COVID-19, in relation to education, among the participants who gave the response as yes, graduates accounted for $41.1 \%$. There was a statistically significant difference with $P=0.0448$ [Table 4]. Regarding practice questions on wearing masks when going outside in relation to education, graduates and undergraduates accounted for $72 \%$ of people who responded as "yes." There was a statistically significant difference with $P=0.0157$ [Table 4].

There was no significant association found between occupation and knowledge of specific medicines and wearing masks when going outside. Age was not a statistically significant factor with regard to fear that one may be get infected with COVID-19 $(P=0.598)$.

\section{Discussion}

Our study is one of the earliest studies in India, evaluating the KAP toward COVID-19 among Indian residents. In this study, it was found that an overall response rate was satisfactory on the knowledge questionnaire, indicating that most respondents are knowledgeable about COVID-19. This can be due to extensive mass media and awareness programs being implemented throughout the nation.

In this study, $81 \%$ of the study participants have good knowledge, which was lower than a study conducted by Zhong et al. among the Chinese population (90\%). ${ }^{[6]}$ It was slightly 
Kutikuppala, et al.: KAP toward COVID-19 among Indian population

\begin{tabular}{|c|c|c|c|}
\hline Serial number & Question & Yes (\%) & No (\%) \\
\hline 1 & COVID-19 can be transmitted by feco-oral route & $588(45.5)$ & $704(54.5)$ \\
\hline 2 & COVID-19 can be transmitted in all areas irrespective of hot or cold climate & $1191(92)$ & $101(8)$ \\
\hline 3 & COVID-19 can be transmitted by mosquito and flies & $84(6.5)$ & $1208(93.5)$ \\
\hline 4 & Antibiotics are effective in the prevention and treatment of COVID-19 & $404(31)$ & $888(69)$ \\
\hline 5 & There are specific medicines to prevent or treat COVID-19 & $130(10)$ & $1162(90)$ \\
\hline 6 & Do you think India can overcome the COVID-19 pandemic? & $1215(94)$ & $77(6)$ \\
\hline 7 & Do you think COVID-19 is highly contagious (transmissible)? & $1256(97.2)$ & $36(2.8)$ \\
\hline 8 & The recovery rate of COVID-19 patients is very high & $722(56)$ & $570(44)$ \\
\hline 9 & Do you have any fear that may be infected with COVID-19 & $253(19.5)$ & $1039(80.5)$ \\
\hline 10 & Do you support the extension of the lockdown & $1230(95.2)$ & $62(4.8)$ \\
\hline 11 & Do you have any fear of financial loss for your family due to COVID-19 & $765(59)$ & $527(41)$ \\
\hline 12 & Are you doing handwash frequently? & $1250(96.7)$ & $42(3.3)$ \\
\hline 13 & Are you maintaining social distancing when going outside? & $1249(96.6)$ & $43(3.4)$ \\
\hline 14 & Are you wearing masks when going outside? & $1263(97.7)$ & $29(2.3)$ \\
\hline 15 & Are you safely disposing the masks after usage? & $1197(92.6)$ & $95(7.4)$ \\
\hline 16 & Have you recently visited a crowded place such as market? & $209(16)$ & $1083(84)$ \\
\hline 17 & Are you following the motto "stay home - stay safe" during the lockdown? & $1279(99)$ & $13(1)$ \\
\hline
\end{tabular}

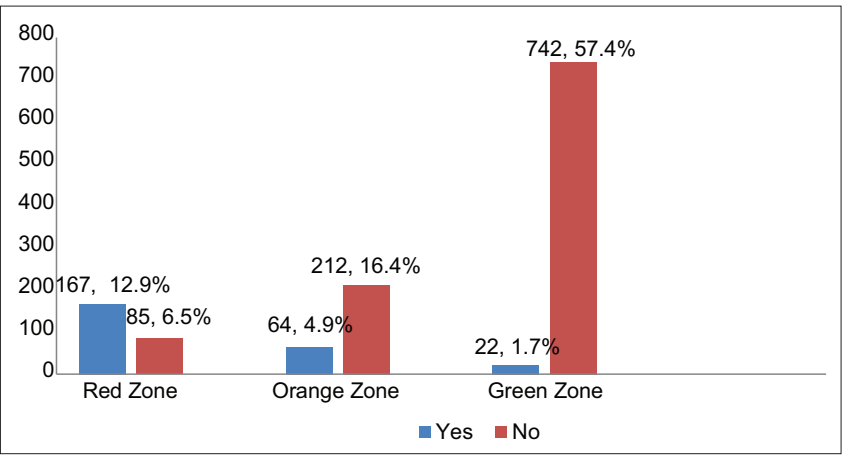

Figure 1: Residing zone versus fear of infection $(n=1292)$

nearer to a study conducted by Olum et al. among Ugandan health-care workers $(82.4 \%)$ and higher than a study conducted by Clements et al. among USA residents $(80 \%) \cdot{ }^{[7,8]}$ In a study by Rugarabamu et al. on Tanzania residents, $84.4 \%$ of the participants had a good knowledge of COVID-19, which was slightly higher than this study $(81 \%) .{ }^{[9]}$

In this study, $94 \%$ of the participants are confident that India can overcome the COVID-19 pandemic, which was lower than a Chinese study (97.1\%) by Zhong et al. ${ }^{[6]}$ Nearly $97.7 \%$ of the participants in our study always wore the mask when they were outside, which was almost equal to a study by Zhong et al. among Chinese population (98\%). In this study, only $16 \%$ of the participants had recently visited crowded places such as markets, which was higher than a study by Zhong et al. among Chinese population (4\%). ${ }^{[6]}$ The KAP studies conducted during past epidemics and pandemics showed less KAP among the study population. A KAP study by Chan et al. among Hong Kong population toward the human A/H7N9 influenza pandemic in 2014 revealed that only $25.3 \%$ of the participants had sufficient knowledge, which was very less compared to the recent KAP studies. ${ }^{[10]}$

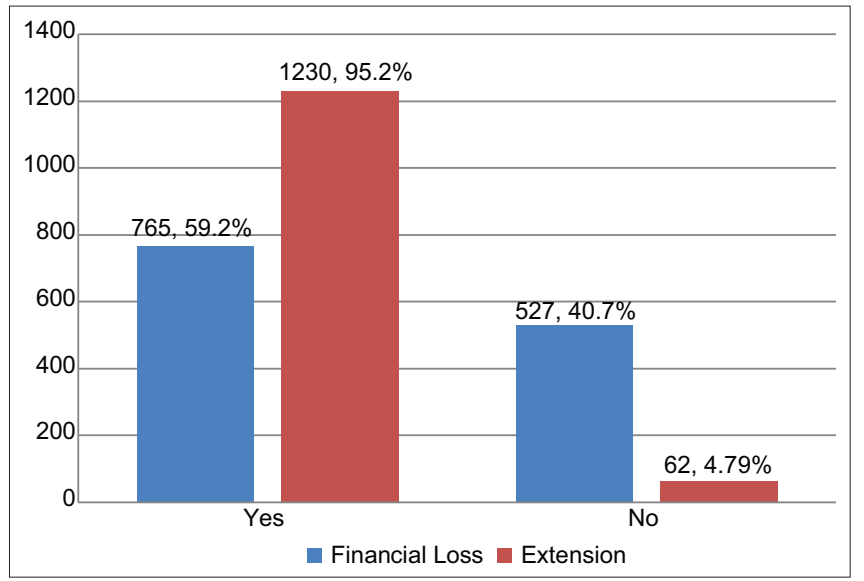

Figure 2: Fear of financial loss versus supporting lockdown extension $(n=1292)$

The study participants are good in overall KAP. They are following all the practices that are mandatory to prevent the COVID-19 infection. The attitude of the Indian population is appreciable as they are very confident in their nation that they can win over COVID-19. The Government of India had taken the decisions wisely that induce a positive attitude among the Indian general population.

\section{Conclusion}

Many factors influence the KAP related to COVID-19 among the general population of India. People with higher educational levels had perceived risk of infection more than other people and took more precautionary behaviors to combat the pandemic. Health education campaigns and awareness events targeting the general population can enhance the knowledge and attitudes of the people to the pandemic and potentiate better practices in facing the crisis. This study could also be used as 


\begin{tabular}{|c|c|c|c|c|c|}
\hline Question & Educational status & $\begin{array}{c}\text { Yes }(n=130) \\
n(\%)\end{array}$ & $\begin{array}{c}\text { No }(n=1192) \\
\quad n(\%)\end{array}$ & $\begin{array}{c}\text { Total }(n=1292) \\
n(\%)\end{array}$ & $P$ \\
\hline \multirow{5}{*}{$\begin{array}{l}\text { Are there any specific medicines } \\
\text { to prevent or treat COVID-19 }\end{array}$} & High school & $5(3.8)$ & $60(5.2)$ & $65(5)$ & \multirow[t]{5}{*}{0.0381 (significant) } \\
\hline & Intermediate/diploma & $11(8.5)$ & $92(8)$ & $103(8)$ & \\
\hline & Undergraduate & $37(28.5)$ & $376(32.3)$ & $413(32)$ & \\
\hline & Graduate & $57(43.8)$ & $460(39.5)$ & $517(40)$ & \\
\hline & Postgraduate & $20(15.4)$ & $174(15)$ & $194(15)$ & \\
\hline Question & Educational status & $\begin{array}{c}\text { Yes }(n=1215) \\
n(\%)\end{array}$ & $\begin{array}{c}\text { No }(n=77) \\
n(\%)\end{array}$ & $\begin{array}{c}\text { Total }(n=1292) \\
n(\%)\end{array}$ & $P$ \\
\hline \multirow{5}{*}{$\begin{array}{l}\text { Do you think India can overcome } \\
\text { the COVID-19 pandemic? }\end{array}$} & High school & $60(4.9)$ & $5(6.5)$ & $65(5)$ & \multirow[t]{5}{*}{0.0286 (significant) } \\
\hline & Intermediate/diploma & $96(7.9)$ & $7(9)$ & $103(8)$ & \\
\hline & Undergraduate & $385(31.7)$ & $28(36.4)$ & $413(32)$ & \\
\hline & Graduate & $490(40.3)$ & $27(35.1)$ & $517(40)$ & \\
\hline & Postgraduate & $184(15.2)$ & $10(13)$ & $194(15)$ & \\
\hline Question & Educational status & $\begin{array}{c}\text { Yes }(n=253) \\
n(\%)\end{array}$ & $\begin{array}{c}\text { No }(n=1039) \\
n(\%)\end{array}$ & $\begin{array}{c}\text { Total }(n=1292) \\
n(\%)\end{array}$ & $P$ \\
\hline \multirow{5}{*}{$\begin{array}{l}\text { Do you have any fear that } \\
\text { you may be get infected with } \\
\text { COVID-19? }\end{array}$} & High school & $11(4.3)$ & $54(5.2)$ & $65(5)$ & \multirow[t]{5}{*}{0.0448 (significant) } \\
\hline & Intermediate/diploma & $19(7.5)$ & $84(8.1)$ & $103(8)$ & \\
\hline & Undergraduate & $77(30.5)$ & $336(32.4)$ & $413(32)$ & \\
\hline & Graduate & $104(41.1)$ & $413(39.7)$ & $517(40)$ & \\
\hline & Postgraduate & $42(16.6)$ & $152(14.6)$ & $194(15)$ & \\
\hline Question & Educational status & $\begin{array}{c}\text { Yes }(n=1263) \\
n(\%)\end{array}$ & $\begin{array}{c}\text { No }(n=29) \\
n(\%)\end{array}$ & $\begin{array}{c}\text { Total }(n=1292) \\
n(\%)\end{array}$ & $P$ \\
\hline \multirow{5}{*}{$\begin{array}{l}\text { Are you wearing masks when } \\
\text { going outside? }\end{array}$} & High school & $64(5)$ & $1(3.4)$ & $65(5)$ & \multirow[t]{5}{*}{0.0157 (significant) } \\
\hline & Intermediate/diploma & $101(8)$ & $2(6.9)$ & $103(8)$ & \\
\hline & Undergraduate & $405(32)$ & $8(27.6)$ & $413(32)$ & \\
\hline & Graduate & $504(40)$ & $13(44.8)$ & $517(40)$ & \\
\hline & Postgraduate & $189(15)$ & $5(17.2)$ & $194(15)$ & \\
\hline
\end{tabular}

imaginary data to monitor public awareness and behaviors in the events of future outbreaks of infectious diseases. Framing the strategies, educational campaigns, and programs to increase public and media awareness is the crucial step in preventing the public weariness toward outbreaks such as COVID-19.

\section{Financial support and sponsorship}

Nil.

\section{Conflicts of interest}

There are no conflicts of interest.

\section{RefERENCES}

1. Suvvari TK, Kutikuppala LV, Babu GK, Jadhav M. Understanding the unusual viral outbreak: Coronavirus disease 2019. J Curr Res Sci Med 2020;6:3-10. [doi: 10.4103/jcrsm.jcrsm_30_20].

2. Report of the WHO-China Joint Mission on Coronavirus Disease 2019 (COVID-19). Available from: https://www.who.int/docs/ default-source/coronaviruse/who-china-joint-mission-on-covid-19final-report.pdf. [Last accessed on 2020 May 22].

3. Novel-Corona Virus Events as They Happen. Available from: https:// www.who.int/emergencies/diseases/novel-coronavirus-2019/ events-as-they-happen. [Last accessed on 2020 May 22].

4. Coronavirus Outbreak. Available from: https://www.worldometers.info coronavirus/. [Last accessed on 2020 May 22].

5. COVID-19 India Official Website. Available from: https://www. covid19india.org/. [Last accessed on 2020 May 22].

6. Zhong BL, Luo W, Li HM, Zhang QQ, Liu XG, Li WT, et al. Knowledge, attitudes, and practices towards COVID-19 among Chinese residents during the rapid rise period of the COVID-19 outbreak: A quick online cross-sectional survey. Int J Biol Sci 2020;16:1745-52.

7. Olum R, Chekwech G, Wekha G, Nassozi DR, Bongomin F. Coronavirus disease-2019: Knowledge, attitude, and practices of health care workers at Makerere University Teaching Hospitals, Uganda. Front Public Health 2020;8:181.

8. Clements JM. Knowledge and behaviors toward COVID-19 among U.S. Residents during the early days of the pandemic. medRxiv 2020;preprint. [doi: 10.1101/2020.03.31.20048967].

9. Rugarabamu S, Byanaku A, Ibrahim M. Knowledge, attitudes, and practices (KAP) towards COVID-19: A quick online cross-sectional survey among Tanzanian residents. medRxiv 2020;Pre-print. [doi: $10.1101 / 2020.04 .26 .20080820]$.

10. Chan EY, Cheng CK, Tam G, Huang Z, Lee P. Knowledge, attitudes, and practices of Hong Kong population towards human A/H7N9 influenza pandemic preparedness, China, 2014. BMC Public Health 2015;15:943. 